\title{
Editorial
}

\section{Las nuevas fronteras del derecho económico internacional}

\author{
Diana MARÍA BELTRÁN VARGAS
}

Para el derecho es un reto adaptarse a la sociedad. Hoy en día esto se hace más evidente si se tiene en cuenta el avance tecnológico y los cambios en la forma en la que se hacen las transacciones; las necesidades de la vida misma cambian más rápido de lo que los Estados, específicamente el regulador, pueden actuar. Sin embargo, un observador cuidadoso puede darse cuenta de nacientes fenómenos y así prever los nuevos retos a los que se enfrentará el derecho sin que resulten ser una sorpresa.

El derecho económico internacional no es una excepción, por lo cual es importante abrir espacios donde los abogados puedan dar voz a situaciones que generarían los grandes debates del mañana. La tecnología es otra muestra de ello. Para que la economía de un país resulte atractiva y competitiva necesita contar, entre otros elementos, con una infraestructura tecnológica que le permita dar solución a diferentes problemas a los que se enfrentan los ciudadanos: el diseño de contratos, la cadena logística para el tránsito de mercancías, los sistemas necesarios para llevar a cabo la solución de controversias y que los bienes y servicios lleguen a los consumidores, entre otros. En este escenario, se requiere que los abogados estén preparados no solo para entender de leyes, sino además de temas mucho más técnicos.

Por otro lado, existen otra serie de fenómenos, cuyo origen es principalmente estructural. Los procedimientos legales previstos, bien sea para generar una norma o para aplicarla, pueden resultar insuficientes y anquilosados para los operadores modernos. Por esta razón, los operadores jurídicos deben estar en capacidad de detectar el origen de dicha situación para cambiarla. Por ejemplo, en cómo se puede garantizar de forma efectiva el acceso a la justicia, sobre todo cuando se habla de mecanismos de solución de controversias que son supranacionales $y$, muchas veces, resultan inalcanzables para el ciudadano común.

En este mismo sentido, las instituciones deben ser capaces de evolucionar cuando las circunstancias así lo requieren. Por ejemplo, los diferentes órganos del Estado pueden 
adoptar roles activos sobre cómo se implementan las obligaciones internacionales adquiridas. De esta manera, se puede alcanzar una sinergia que garantice la armonía entre el derecho doméstico y el internacional.

Con esto no se quiere decir que los operarios jurídicos deban actuar como oráculos y predecir cada una de las vicisitudes futuras. A veces solo basta con identificar nacientes fenómenos para prever sus efectos y sugerir cómo el derecho encaja en estos escenarios, las soluciones que puede ofrecer. Es importante oír las voces tanto de académicos como de practicantes sobre problemáticas contemporáneas para entender el alcance que estas pueden llegar a tener.

Teniendo en cuenta lo anterior, un espacio como el del Premio Jurista Global resulta más que pertinente. En esta labor conjunta, entre el Departamento de Derecho Económico de la Universidad Externado de Colombia y la Universidad de Zaragoza, se creó un espacio para que los jóvenes abogados analicen cómo ven algunas problemáticas del derecho económico internacional y los efectos que pueden tener en la década que está por comenzar. Asuntos no solo relacionados con la tecnología, sino también con las instituciones, el acceso a la justicia e incluso las consecuencias de la pandemia.

Agradecemos a todos aquellos que respondieron a la convocatoria con sus textos. En ellos se reflexionó sobre distintos problemas y se hizo un análisis sobre qué le depara el futuro al derecho económico internacional. Las publicaciones que se encuentran en este número son aquellos trabajos sobresalientes en los que se analizaron temas contemporáneos, cuyos efectos serán más que comunes en algunos años, sino lo son ya. 